OPEN ACCESS

Edited by:

Waganesh A. Zeleke

Duquesne University, United States

Reviewed by:

Sofia Mavropoulou,

Queensland University of Technology,

Australia

Christoforos Mamas,

University of California, San Diego,

United States

*Correspondence:

Susanne Schwab

susanne.schwab@univie.ac.at

Specialty section

This article was submitted to

Special Educational Needs,

a section of the journal

Frontiers in Education

Received: 17 June 2020

Accepted: 07 April 2021

Published: 29 April 2021

Citation:

Schwab S, Lehofer M and Tanzer N (2021) The Impact of Social Behavior and Peers' Attitudes Toward Students With Special Educational

Needs on Self-Reported Peer Interactions. Front. Educ. 6:561662. doi: 10.3389/feduc.2021.561662

\section{The Impact of Social Behavior and Peers' Attitudes Toward Students With Special Educational Needs on Self-Reported Peer Interactions}

\author{
Susanne Schwab ${ }^{1,2 *}$, Mike Lehofer ${ }^{1}$ and Norbert Tanzer ${ }^{3}$ \\ ${ }^{1}$ Centre of Teacher Education, University of Vienna, Vienna, Austria, ${ }^{2}$ Research Focus Area Optentia, North-West University, \\ Vanderbijlpark, South Africa, ${ }^{3}$ Institute of Psychology, University of Graz, Graz, Austria
}

According to the literature, social participation (e.g., peer interactions) of students diagnosed with special educational needs (SEN) has to be focused upon as they are at a higher risk of being socially excluded compared to students without SEN. Research has pointed out that social participation of students with SEN is influenced by their own social behavior as well as the attitudes of peers with no SEN toward them. The present study assessed the impact of the social behavior of students diagnosed with SEN ( $n=88 ; 48$ boys and 40 girls) as well as that of the attitudes of their peers without SEN ( $n=227 ; 139$ boys and 153 girls) toward them on the social participation. Results indicated that students without SEN were less likely to interact with their classmates with SEN. Peer interactions of students with SEN were not significantly influenced by their own social behavior.

Keywords: students, behavior disorders, special educational needs, attitudes, peer interaction

\section{INTRODUCTION}

According to the European policy (see Schwab, 2020 for an overview), inclusive education refers to the enhancement of the developmental opportunities of all students and the removal of different types of barriers. Students diagnosed with special education needs $\left(\mathrm{SEN}^{1}\right)$ are particularly focused on as a target group in research as there is a long history of educating them in special classes. The present paper refers to inclusive education in terms of physically and socially including students with SEN in mainstream classes. In Austria more than half of the students with SEN are nowadays educated in mainstream classes; their parents can decide whether they attend mainstream classes or special classes (for an overview of the Austrian inclusive educational system, see Schwab, 2014, 2018a). One reason why parents do not choose mainstream schools is the concern that their child could be socially excluded.

\section{Social Participation of Students With and Without SEN}

The term "social participation" comprises relevant social aspects of inclusion and includes the following as core themes: students' social interactions (e.g., spending time together while working on a project or during breaks), peer acceptance, friendships, and self-perception of social inclusion

\footnotetext{
${ }^{1}$ Within this study the term SEN refers to students with a diagnosis of SEN rather than to those having SEN. There is a lack of reliability and transparency in the criteria of diagnosed SEN within research. In other words, since students with undiagnosed SEN are often not considered in empirical studies, this term rather tends to include those students who are officially diagnosed with SEN (see Schwab, 2020). Moreover, having a disability (in Austria) does not necessarily mean that a student has SEN.
} 
(e.g., feeling lonely) (see the reviews of Koster et al., 2009; Bossaert et al., 2013). To summarize the results of recent literature reviews (Koster et al., 2009; Bossaert et al., 2013; Schwab, 2018b), the social participation of students with SEN is lower compared to their peers without SEN. The reviews showed that students with SEN have lower peer acceptance, fewer friendships, and less peer interactions compared to students without SEN. Mamas et al. (2020) demonstrated that students with SEN were less likely to receive friendship nominations from their peers. Nepi et al. (2015) showed in their study that students with SEN are rarely chosen as favored classmates by their peers without SEN. With specific focus on peer interactions, usually operationalized as time spent together, the literature clearly shows that students with SEN have fewer interactions with classmates than their peers without SEN (e.g., Schwab, 2015; Henke et al., 2017; Petry, 2018). A study by Schwab (2017) revealed that students with SEN are less frequently chosen by their peers for joint activities, such as working together on a school project. However, differences within a group (e.g., students with SEN) are often higher than differences between groups (e.g., students with and without SEN). In light of these results, it is particularly important to identify opportunities to promote social participation of students with SEN (see Hassani et al., 2020). Many factors may play a role in determining social participation of students: e.g., factors within the student, within the educational environment (educational processes), and classroom-related or contextual factors. A crucial way to foster students' social participation is to improve individual student variables, such a students' attitudes and/or their social behavior (see the review of Hassani et al., 2020). Within the framework of this study, the focus will be on the social behavior of students with SEN and without SEN as well as on students' attitudes toward peers with special needs. Therefore, factors at the individual level (of students) as well as within the educational environment (e.g., attitudes and social behavior of class members) will be addressed in the present paper.

\section{Students' Social Behavior and Its Impact on Social Participation}

Based on the literature (see Schwab et al., 2015a), the presence of pro-social behavior and the absence of behavioral problems in students with SEN seem to be particularly important for social participation. Studies have shown that students with SEN (particularly those with learning disabilities) show more aggressive behavior and less pro-social behavior compared to their peers without SEN (for an overview, see Schwab, 2014). Mand (2007) observed that students with behavioral problems were rather unpopular in both inclusive and special education systems and thereby concluded that social behavior plays a prominent role in social participation. According to the results by Schwab (2014), social participation of students is mainly determined by their social behavior and social skills. Sociometric studies have provided evidence that popular students show more positive associated social behavior, whereas socially rejected students show significantly more negative associated behavior (e.g., aggressive behavior) than averagely rated students (e.g., Newcomb et al., 1993; Jones and Frederickson, 2010). These results can be underpinned by research in other contexts: For instance, the results of the study by Lu et al. (2018) show the strong relation between aggressive behavior and students' popularity in middle and high schools.

\section{Students' Attitudes Toward Peers With SEN and Its Impact on Social Participation}

According to Allport, 1935, 810) attitude is described as "A mental and neural state of readiness, organized through experience, exerting a directive or dynamic influence upon the individual's response to all objects and situations with which it is related." Within the definition of attitude, reference is mostly made to three components: the affective component (which indicates feelings), the behavioral component (which is related to intentions) and the cognitive component (beliefs) (see Eagly and Chaiken, 1998). Grütter et al. (2018) analyzed cross-group friendships between students with average academic achievement and students with low academic achievement. The authors showed that these intergroup friendships increase the social participation of low-achieving students due to the resulting increase in sympathy and intergroup trust.

Changes in students' intergroup attitudes can be explained with the intergroup contact theory, according to which a stigmareducing effect of contact on attitudes can be assumed (Allport, 1954; Pettigrew and Tropp, 2000). Empirical evidence for this theory has been shown through several studies in the context of SEN (MacMillan et al., 2013; Armstrong et al., 2016a; de Boer and Pijl, 2016; Schwab, 2017; Petry, 2018) or student achievement (Grütter et al., 2018; see also the review of MacMillan et al., 2013). However, not all studies found evidence that students' attitudes toward peers with SEN influence the social participation of students with SEN (Petry, 2018). One explanation for the inconsistent findings could be that it is not the quantity but rather the quality of contact that is associated with more positive attitudes (Keith et al., 2015; Schwab, 2017). Within the theory of planned behavior (Ajzen, 1991), it is assumed that attitudes explain people's behavior. Moreover, according to the framework of the cognitive dissonance theory of Festinger (1957), people want to avoid disharmony in attitudes and beliefs. This might explain why students with more negative attitudes toward peers with SEN avoid having contact with them.

There is little literature investigating whether there are class composition effects in peers' attitudes toward students with SEN. Petry (2018) examined the link between class members' mean attitudes in relation to peer interactions and showed an effect on students with sensory and/or motor limitations. However, no effect was found on students with autism spectrum disorder.

\section{OBJECTIVES OF THE STUDY}

Despite the knowledge currently available from cross-sectional studies about lower peer interactions of students with SEN in general education, there is still a lack of information about variables that promote the social participation of students with SEN (de Boer et al., 2013). For instance, hardly any studies 
examine if mean attitudes in class (as an indicator of social norm) influence individual peer attitudes (Schwab, 2018a). The current study sought to examine the following hypotheses:

1. Social behavior of students with SEN predicts the interactions between students with and without SEN.

2.a. Individual attitudes of students without SEN toward peers with SEN predict the interactions between students with and without SEN.

2.b. The mean class attitude of students without SEN toward peers with SEN predict the interactions between students with and without SEN.

\section{MATERIALS AND METHODS}

\section{Research Design}

The current study is part of the longitudinal research project "Attitudes Toward Inclusion of Students with Disabilities related to Social Inclusion" (ATIS-SI). Data were collected from primary and secondary school students (fourth and seventh graders, respectively). The fourth grade was chosen as it is the last year of primary education in Austria and students know each other for three years by this point. The seventh grade was chosen from secondary school as the students know each other for at least two years by this time. Since students with SEN sometimes repeat classes, the number of students with SEN in seventh grade was expected to be higher than in the eighth grade. Besides, students with SEN may already have completed the required nine years of compulsory school in Austria. However, the exact duration of placement of students with disability in these classes was not assessed in this project.

Data for the ATIS-SI study were collected at three measurement points. At the first measurement point (T1; beginning of the school year), fourth and seventh graders from three Austrian Federal States, Styria, Lower Austria and Burgenland, participated in the paper-and-pencil survey. The second measurement point (T2) was at the end of the school year. In addition, a questionnaire was also completed by secondary school students (the former seventh graders) at the end of grade eight (T3). However, since student in the primary schools moved to different secondary schools after T2, data for T3 are not available for this subsample. The series of questionnaires encompassed topics such as social participation, social behavior, and attitudes toward peers with SEN. At each measurement point, students spent approximately $50 \mathrm{~min}$ to complete the questionnaires. The data were collected by trained research assistants. A team of two or three trained research assistants supported students in filling out the paper-pencil questionnaires. They also assisted those students who had difficulties (e.g., they read the questions for students with reading difficulties).

\section{Study Procedure}

For the current study, data from T1 to T2 were used. At T1, 63 classes participated in the paper-and-pencil survey. At T2, 60 of those classes participated again. Only those students who completed the questionnaires at both measurement points (T1 and T2) were included in the analysis. However, only a subset of the ATIS-SI data was used in this study because around half of the sample contained data from regular classes (in which no students with SEN diagnosis are taught). Further, for the current study, only ratings from students without SEN regarding their interactions and attitudes toward peers with SEN were included. As such, the ratings of students with SEN about their interactions with peers (and their attitudes toward peers with SEN) were not included in the analysis. This was done because of the interest in inter-group effects rather than in intra-group effects. However, students' social behavior ratings for the subsample of students with SEN were included in the analyses. Further, the female sample included only the ratings for female peers, while the male sample included only the ratings for male peers. The rational for this decision was that previous literature already indicated differences in friendship patterns related to gender (see e.g., Mjaavatn et al., 2016). Example, it was already shown that social interactions of students mostly occur within same gender groups (e.g., Underwood, 2004). In addition, in classes with only one student with SEN, either the girls or the boys without SEN (depending on the sex of the student with SEN) were excluded from further calculations.

\section{Ethical Approval}

The research was approved by the Regional School Authorities of Styria, Lower Austria and Burgenland and informed consent was obtained from all participants completing the questionnaires and their parents.

\section{Participants}

The sample for the present study consisted of 292 students without SEN (153 girls and 139 boys; 66.4\% fourth graders, $33.6 \%$ secondary graders) from 20 primary (fourth graders, approximately 9-11 years old) and secondary (seventh graders, approximately 12-14 years old) school classes from Austria. These students rated 88 students with SEN (40 girls and 48 boys). About $10.5 \%$ of the students in the sample were born outside Austria. Additionally, more than $30 \%$ of the students in the sample speak a language other than German with their parents. Generally, in Austria, as in many countries, students from a migrant background and with lower socioeconomic status are overrepresented in the subsample of students with SEN (see Gebhardt et al., 2013). Moreover, in Austria, up to five students with SEN are in one class, and in most of the Austrian inclusive classes two teachers (a regular and a special needs teacher) teach together. In addition, as George and Schwab (2019) demonstrated using a nation-wide sample in inclusive classes in Austria, students with low socioeconomic status, students of parents with low educational levels as well as students with non-German-speaking parents are overrepresented in Austrian inclusive classes.

\section{Measures}

\section{Special Educational Needs (SEN) With Respect to Learning (T1)}

In Austria, students with SEN need an official statement from the local educational authority to qualify for additional resources 
(see Schwab, 2018a). Since in the present study most students with diagnosed SEN had SEN related to learning disabilities ${ }^{2}$ (more than $80 \%$ ) and only a very small number of students with SEN had other types of SEN (e.g., behavioral disorders), it was not possible to perform calculations for different subgroups of students with SEN.

\section{Social Behavior of Students (T1 Only)}

One of the instruments most frequently used to assess the behavioral problems of students is the Strengths and Difficulties Questionnaire (SDQ; Goodman and Goodman, 2011), which assesses students' behavioral problems from different perspectives (e.g., self-perspective, parents' or teachers' view). In the current study, the self-perspective version for children was used. ${ }^{3}$ The SDQ consists of 25 items, five items per subscale (emotional symptoms, conduct problems, hyperactivity/inattention, peer relationship problems, and prosocial behavior), to be answered on a 3-point Likert scale (not true $=0$, somewhat true $=1$, certainly true $=2$ ). Satisfactory reliability and a replicable factor structure of this have been shown in previous research (Klasen et al., 2000). Further, Schwab et al. (2015c) showed that the SDQ is also acceptable for a slightly younger sample (students aged 9). Moreover, researchers have already shown that the student version of the SDQ is suitable for students with and without SEN (see DeVries et al., 2018). The Cronbach's Alpha for the SDQ problem score within the ATIS-SI study was.75. For the purpose of this study, the peer relationship problems scale was not included. The scores for the other four SDQ subscales were standardized.

\section{Attitudes Toward Students With SEN With Respect to Learning Disabilities (T1 and T2)}

Attitudes toward students with SEN (i.e., with learning disabilities) were assessed using a short German version (Schwab, 2015) of the Chedoke-McMaster Attitudes toward Children with Handicaps Scale (CATCH; see also Rosenbaum et al., 1986). First, students had to read a brief case description. Girls were given a female version (with a female character) and boys were given a male version. The female case was introduced as follows (Schwab, 2015, 180): "Susanne has just moved to your city and goes to the same school as you. Susanne has great difficulties with reading, writing, and mathematics. She needs more time to solve exercises than other children." These vignettes are used to avoid stigmatizing effects through the use of negatively connoted words such as "disability." Moreover, the concept of learning disabilities may not be clear to school children; therefore, describing an

\footnotetext{
${ }^{2}$ In Austria, students with learning difficulties do not include those with specific learning difficulties such as dyslexia or dyscalculia. The category "learning difficulties" rather refers to students with lower academic competences in all subjects and lower intelligence scores compared to their peers (for a detailed information about learning difficulties in Austria, see Gebhardt et al., 2013). Generally, within the group of students with SEN, the proportion of students with SEN related to learning disabilities is highest in Austria (see Schwab et al., 2015b). Moreover, within this study, students with some disabilities (e.g., severe mental disabilities) were not included as the study design was inappropriate for this subsample.

${ }^{3}$ The self-version was used to avoid missing some information (teacher ratings were not available for all students).
}

unknown case seems more appropriate. Students had to answer the six items of the short version of the CATCH on a 5-point rating scale (never $=1$, rarely $=2$, sometimes $=3$, often $=4$, always $=5$ ) measuring the affective and behavioral components of attitudes (e.g., "I would feel good doing a school project with Susanne"). This version was built up from a previous sevenitem version of Bossaert and Petry (2013) in which five items belong to the affective component and two items to the behavioral component. The cognitive subscale was not used as other research has shown that this subscale does not create a unidimensional and internally consistent scale (Armstrong et al., 2016b). The psychometric qualities (i.e., unidimensional factor structure and measurement invariance between students with SEN versus students without SEN, as well as high reliability) of this short German version have been demonstrated by Schwab (2015). One item was deleted as the confirmatory factor analysis showed that the item fit is higher when removing this item. The results of the confirmatory factor analysis indicated a good fit for the six-item version and the reliability (Cronbach's Alpha) was above 9 (for more details, see Schwab, 2015). Further, Schwab (2015) showed that there is no measurement bias between students with and without SEN for this scale. The Cronbach's Alpha for T1 was 80 and $\mathrm{T} 2$ was 85 . For the purpose of this study, a standardized mean score $(M=0, \mathrm{SD}=1)$ of the six items was used.

\section{Peer Interaction (T1 and T2)}

A peer rating method was used as a criterion (dependent variable) since this method is a powerful tool for measuring students' social participation. Students (without $\mathrm{SEN}^{4}$ ) were asked to indicate their response to the following question on a 5-point scale (never $=1$, rarely $=2$, sometimes $=3$, often $=4$, always $=5$ ): "How often do you interact with each of your classmates during breaks? " A list with the names of all peers was provided so that students could rate them. For the analysis of peer interaction with students with SEN, the same-sex ratings of each student without SEN toward their peer with SEN was used.

\section{Statistical Analysis}

Based on the results of de Boer et al. (2013) as well as on literature about same-sex preference in friendships (see Aboud and Mendelson, 1996), it seems that gender plays an important role in the social participation of students with SEN. Female/male vignettes were used to assess the attitudes toward peers with SEN (see Schwab, 2015) to avoid gender effects (e.g., girls might generally have more negative attitudes toward boys compared to girls). Moreover, it might be the case that constructs (e.g., intergroup effects; peer influences) function differently for girls and boys. Therefore, this study focused on same-sex results and data for girls and boys were analyzed separately. For girls, the dependent variable was the peer interaction of girls without SEN with girls with SEN. Similarly, for boys, the dependent variable was the peer interaction of boys without SEN with boys with SEN.

The hierarchically nested structure of our data was taken into account by multilevel regression analyses of peer interaction

\footnotetext{
${ }^{4}$ For the data analysis of this study, only the ratings of students without SEN were used. However, students with SEN participated at the data collection too and filled out the identical questionnaires.
} 
(Level 2: classes, Level 1: students; see also de Boer et al., 2013). For both hypotheses, we used a multilevel model without entering any predictors (null model) to estimate the variance in Level 2 versus Level 1 and to calculate the size of the intraclass correlations (ICCs, reported in Table 1). The ratings of students without SEN have been used as dependent variables within these analyses.

For Hypothesis 1, a multilevel model (Level 2: classes) was employed with the social behaviors of students with SEN (along with grade) as predictors and their peer interactions, as reported by students without SEN, as outcome variables (see Tables 2-4).

For Hypothesis 2, a multilevel model (Level 2: classes) was used with the individual and class mean social attitudes of the students without SEN (together with grade) as predictors (see Tables 5-7) and their reports on their peer interactions with students with SEN as the outcome variable.

Moreover, for both hypotheses, a cross-sectional analyses (see Tables 2, 3, 5, 6) as well as longitudinal analyses (see

TABLE 1a | Means, standard deviations, and intra-class correlations (ICC) for peer interaction of boys with SEN versus boys without SEN as reported by boys without SEN (T1).

\begin{tabular}{lcccc}
\hline Group & $\boldsymbol{M}$ & SD & $\boldsymbol{n}$ & $\boldsymbol{I C C}$ \\
\hline Boys with SEN & 2.58 & 1.38 & 48 & $0.42^{\mathrm{a}}$ \\
Boys without SEN & 3.20 & 1.38 & 139 & $0.45^{\mathrm{a}}$ \\
\hline
\end{tabular}

${ }^{a}$ The ICCs were calculated without explanatory variables.

TABLE 1b | Means, standard deviations, and intra-class correlations (ICC) for peer interaction of girls with SEN versus girls without SEN by as reported girls without SEN (T1).

\begin{tabular}{lcccc}
\hline Group & $\boldsymbol{M}$ & SD & $\boldsymbol{n}$ & ICC \\
\hline Girls with SEN & 2.40 & 1.32 & 40 & $0.24^{\mathrm{a}}$ \\
Girls without SEN & 3.14 & 1.42 & 153 & $0.41^{\mathrm{a}}$ \\
\hline
\end{tabular}

${ }^{a}$ The ICCs were calculated without explanatory variables.

TABLE 2 | Influence of social behavior of students with SEN at T1 on their peer interactions during breaks at $\mathrm{T} 1$ as reported by boys or girls without SEN.

\begin{tabular}{|c|c|c|c|c|}
\hline \multirow[b]{2}{*}{ Parameter } & \multicolumn{2}{|c|}{ Boys $(n=48)$} & \multicolumn{2}{|c|}{ Girls $(n=40)$} \\
\hline & Estimate & SE & Estimate & SE \\
\hline \multicolumn{5}{|l|}{ Fixed Effects } \\
\hline Intercept & 1.93 & 0.78 & 1.96 & 0.60 \\
\hline Grade & 0.35 & 0.41 & 0.34 & 0.35 \\
\hline Emotional Symptoms ${ }^{a}$ & -0.03 & 0.16 & -0.27 & 0.15 \\
\hline Conduct Problems ${ }^{\mathrm{a}}$ & -0.11 & 0.14 & -0.08 & 0.14 \\
\hline Hyperactivity/Inattention ${ }^{\mathrm{a}}$ & 0.14 & 0.17 & 0.27 & 0.18 \\
\hline Pro-social Behavior ${ }^{\mathrm{a}}$ & 0.05 & 0.18 & 0.06 & 0.13 \\
\hline \multicolumn{5}{|c|}{ Random Effects (Residual Variances) } \\
\hline Class-level & $-\mathrm{b}$ & - & $-\mathrm{b}$ & - \\
\hline Student-level & $1.09^{\star \star}$ & 0.25 & 0.69 & 0.19 \\
\hline
\end{tabular}

a Standardized scores as reported by students without SEN at T1. ${ }^{b}$ Could not be estimated, ${ }^{* *} p<0.01$
Tables 4,7$)$ were conducted. In the cross-sectional analysis both, the predictors and the dependent variable (peer interaction), came from either T1 or T2, whereas in the longitudinal analysis the predictors came from T1 and the dependent variable from T2.

In the multilevel analysis, the metric variables were grandmean centered.

\section{RESULTS}

Tables 1a, b show the means, standard deviations and intraclass correlations (ICCs indicating the variance in class level) for peer interactions during breaks. For both genders, the means show that during breaks, students without SEN interact less frequently with their classmates with SEN than they do with their classmates without SEN. The size of the ICCs further indicates variation between classes in the frequency of peer interactions during breaks. Compared to the other ICCs (0.41-0.45), the lower ICC for peer interactions of girls with SEN $($ ICC $=0.24)$

TABLE 3 | Influence of social behavior of students without SEN at T1 on their peer interactions during breaks at $\mathrm{T} 1$ as reported by boys or girls without SEN.

\begin{tabular}{|c|c|c|c|c|}
\hline \multirow[b]{2}{*}{ Parameter } & \multicolumn{2}{|c|}{ Boys $(n=139)$} & \multicolumn{2}{|c|}{ Girls ( $n=153$ ) } \\
\hline & Estimate & SE & Estimate & SE \\
\hline \multicolumn{5}{|l|}{ Fixed Effects } \\
\hline Intercept & 3.70 & 0.27 & 3.58 & 0.22 \\
\hline Grade & -0.19 & 0.17 & -0.19 & 0.14 \\
\hline Emotional Symptoms ${ }^{a}$ & -0.01 & 0.04 & $-0.08^{\star}$ & 0.03 \\
\hline Conduct Problems ${ }^{a}$ & $-0.10^{\star \star}$ & 0.04 & $-0.12^{\star \star}$ & 0.03 \\
\hline Hyperactivity/Inattention ${ }^{a}$ & 0.00 & 0.04 & $0.11^{\star \star}$ & 0.03 \\
\hline Pro-social Behaviora & -0.06 & 0.04 & 0.04 & 0.03 \\
\hline \multicolumn{5}{|c|}{ Random Effects (Residual Variances) } \\
\hline Class-level & $0.30^{\star \star}$ & 0.07 & $0.19^{\star \star}$ & 0.05 \\
\hline Student-level & $0.38^{\star \star}$ & 0.03 & $0.29^{\star \star}$ & 0.02 \\
\hline
\end{tabular}

TABLE 4 | Influence of social behavior of students with SEN at T1 on their peer interactions during breaks at T2 as reported by girls or boys without SEN.

\begin{tabular}{|c|c|c|c|c|}
\hline \multirow[b]{2}{*}{ Parameter } & \multicolumn{2}{|c|}{ Boys $(n=48)$} & \multicolumn{2}{|c|}{ Girls $(n=40)$} \\
\hline & Estimate & SE & Estimate & SE \\
\hline \multicolumn{5}{|l|}{ Fixed Effects } \\
\hline Intercept & 2.77 & 0.66 & 2.51 & 0.78 \\
\hline Grade & -0.23 & 0.37 & 0.06 & 0.46 \\
\hline Emotional Symptoms ${ }^{a}$ & 0.20 & 0.13 & -0.27 & 0.18 \\
\hline Conduct Problems ${ }^{a}$ & -0.20 & 0.11 & -0.16 & 0.17 \\
\hline Hyperactivity/Inattention ${ }^{a}$ & $0.35^{\star}$ & 0.15 & 0.33 & 0.21 \\
\hline Pro-social Behaviora & 0.28 & 0.15 & -0.06 & 0.17 \\
\hline \multicolumn{5}{|c|}{ Random Effects (Residual Variances) } \\
\hline Class-level & 0.23 & 0.19 & 0.19 & 0.27 \\
\hline Student-level & $0.35^{\star \star}$ & 0.13 & $0.72^{\star \star}$ & 0.28 \\
\hline
\end{tabular}


TABLE 5 | Influence of attitudes toward students with SEN at T1 on peer interactions during breaks at $\mathrm{T} 1$ as reported by boys or girls without SEN.

\begin{tabular}{|c|c|c|c|c|}
\hline \multirow[b]{2}{*}{ Parameter } & \multicolumn{2}{|c|}{ Boys $(n=139)$} & \multicolumn{2}{|c|}{ Girls ( $n=153$ ) } \\
\hline & Estimate & SE & Estimate & SE \\
\hline \multicolumn{5}{|l|}{ Fixed Effects } \\
\hline Intercept & 2.81 & 0.71 & 2.04 & 0.42 \\
\hline Grade & -0.01 & 0.39 & 0.26 & 0.23 \\
\hline $\mathrm{CATCH}^{\mathrm{a}}$ & $0.15^{\star}$ & 0.07 & 0.17 & 0.09 \\
\hline CATCH Class Mean & 0.59 & 0.42 & $-0.67^{\star}$ & 0.29 \\
\hline \multicolumn{5}{|c|}{ Random Effects (Residual Variances) } \\
\hline Class-level & $0.54^{\star}$ & 0.22 & 0.07 & 0.08 \\
\hline Student-level & $0.77^{\star \star}$ & 0.10 & $1.11^{\star \star}$ & 0.13 \\
\hline
\end{tabular}

during breaks is noteworthy. Nevertheless, the size of all ICCs underlines the need for multilevel analyses instead of regular multiple regression analyses.

\section{Hypothesis 1: The peer interactions of students with SEN during} breaks can be predicted by their social behavior

To investigate this hypothesis, three multilevel analyses were conducted, the first two for cross-sectional data and the third for longitudinal data. Table 2 shows the results of the crosssectional analysis for students with SEN. In order to provide a reference point for interpreting these results, the same multilevel analyses were conducted for students without SEN (see Table 3). Finally, a longitudinal analysis for students with SEN using the behavior scores from $\mathrm{T} 1$ as predictors and the peer interactions during breaks of students with SEN at T2 as criterion (see Table 4) were performed.

As can be seen in Table 2, the peer interaction of students with SEN is not significantly influenced by their own social behavior. Table 3 shows the results of the same multilevel analyses, but now conducted for students without SEN. While there are some significant effects of social behavior, the effects are nevertheless relatively small (all $\beta s \leq|0.12|$ ). For boys, conduct problems negatively influenced peer interactions during breaks; for girls, conduct problems as well as hyperactivity and emotional symptoms predicted peer interactions during breaks. A positive link was found for hyperactivity, indicating that higher hyperactivity is associated with more interaction.

Finally, Table 4 shows the results of the longitudinal analysis. For girls with SEN, the results resemble those of the crosssectional analysis. For boys with SEN, however, an unexpected effect arises: The higher the hyperactivity of students with SEN $(\beta=0.35, p<0.05)$ the more their peer interaction with their male peers.

Hypothesis 2: The peer interactions of students with SEN during breaks can be predicted by (a) the individual attitudes of students without SEN toward peers with SEN and/or (b) the respective class means
TABLE 6 | Influence of attitudes toward students with SEN at T2 on peer interactions during breaks at T2 as reported by boys or girls without SEN.

\begin{tabular}{|c|c|c|c|c|}
\hline \multirow[b]{2}{*}{ Parameter } & \multicolumn{2}{|c|}{ Boys $(n=139)$} & \multicolumn{2}{|c|}{ Girls $(n=153)$} \\
\hline & Estimate & SE & Estimate & SE \\
\hline \multicolumn{5}{|l|}{ Fixed Effects } \\
\hline Intercept & 3.05 & 0.72 & 2.82 & 0.69 \\
\hline Grade & -0.02 & 0.41 & -0.16 & 0.40 \\
\hline $\mathrm{CATCH}^{\mathrm{a}}$ & 0.00 & 0.09 & 0.06 & 0.10 \\
\hline CATCH Class Mean & $1.38^{\star}$ & 0.63 & -0.20 & 0.57 \\
\hline \multicolumn{5}{|c|}{ Random Effects (Residual Variances) } \\
\hline Class-level & $0.54^{\star}$ & 0.24 & $0.49^{\star}$ & 0.24 \\
\hline Student-level & $0.80^{\star \star}$ & 0.11 & $1.06^{\star \star}$ & 0.14 \\
\hline
\end{tabular}

TABLE 7 | Influence of attitudes toward students with SEN at T1 on peer interactions during breaks at T2 as reported by boys or girls without SEN.

\begin{tabular}{|c|c|c|c|c|}
\hline \multirow[b]{2}{*}{$\begin{array}{l}\text { Parameter } \\
\text { Fixed Effects }\end{array}$} & \multicolumn{2}{|c|}{ Boys $(n=139)$} & \multicolumn{2}{|c|}{ Girls ( $n=153)$} \\
\hline & Estimate & SE & Estimate & SE \\
\hline Intercept & 2.91 & 0.73 & 2.61 & 0.64 \\
\hline Grade & 0.01 & 0.42 & -0.03 & 0.37 \\
\hline $\mathrm{CATCH}^{\mathrm{a}}$ & 0.03 & 0.08 & -0.04 & 0.11 \\
\hline CATCH Class Mean ${ }^{a}$ & 0.86 & 0.48 & -0.58 & 0.44 \\
\hline \multicolumn{5}{|c|}{ Random Effects (Residual Variances) } \\
\hline Class-level & $0.56^{\star}$ & 0.25 & 0.37 & 0.20 \\
\hline Student-level & $0.78^{\star \star}$ & 0.11 & $1.12^{\star \star}$ & 0.14 \\
\hline
\end{tabular}

${ }^{a}$ As reported by students without SEN at T1, ${ }^{*} p<0.05,{ }^{* *} p<0.01$.

To investigate this hypothesis, three multilevel analyses were conducted: the first two for the cross-sectional data (see Tables 5, 6, respectively) and the third one for the longitudinal data (Table 7). For boys, positive attitudes toward male peers with SEN significantly predict their peer interaction, either through individual attitudes at T1 $(\beta=0.15, p<0.05)$ or average class attitudes at T2 $(\beta=1.38, p<0.05)$. For girls, however, negative attitudes toward female peers with SEN significantly predict their peer interaction with them at T1 $(\beta=-0.67, p<0.01)$ but not at T2 $(\beta=-0.20, p>0.10)$. Finally, as can be seen in Table 7 , the longitudinal analysis showed no significant results. Although not significant, the average class attitudes also predict peer interaction in the cross-sectional analysis of T1 $(\beta=0.59)$ as well as the longitudinal analysis $(\beta=0.86)$.

\section{DISCUSSION}

In line with previous studies, this study shows that students with SEN in inclusive educational settings are not automatically socially included. The results show that peers with no SEN interact less frequently with peers with SEN than they do with peers without SEN. Given the highly negative impact of low social participation on students' academic, social, emotional, and mental health development (Låftman and Östberg, 2006; 
Kidger et al., 2012), this problem should be addressed and given a much higher priority in schools. In this study, the variance in peer interactions in terms of class levels indicates that there are classes which handle the social participation of students with SEN better, while other classes have greater difficulties. One explanation for the low levels of interaction of students without SEN with their peers with SEN during breaks could be that, in some cases, teachers spend time with students with SEN during the breaks. They try to finish exercises with them or explain to them what they did not understand during the lesson (see Bajzek et al., 2014), etc. Although it is important to make sure that all students keep track of what was thought during class, a practical recommendation would be for teachers to give students with SEN the chance to interact with their peers during breaks. To prove this assumption, future research should observe students and their teachers during breaks to identify possible factors hindering the interactions between peers with and without SEN. Additionally, results of this study clearly underpinned that social interactions in inclusive classrooms need to be promoted actively (see e.g., Mamas and Avramidis, 2013). Another explanation could be that it is not the environment but the social behavior of students with SEN that predicts their low peer interactions. This was analyzed within hypothesis 1 . For cross-sectional data, no link between the peer interaction of students with SEN (boys and girls) and their social behavior (emotional symptoms, conduct problems, hyperactivity/inattention, pro-social behavior) was found. In comparison, for students without SEN, some significant effects of social behavior on their peer interactions were found. Maybe Hypothesis 1 (the peer interactions of students with SEN during breaks can be predicted by their social behavior) remained unsupported due to a methodological weakness of the study. To examine this hypothesis a self-perspective version of SDQ for children was used to assess students' social behavior. However, results from Schwab et al. (2016) lead to the conclusion that students with SEN show a tendency to underestimate their own peer problems when using the SDQ. Finally, the results of the longitudinal analysis show that for boys with SEN, hyperactivity predicts more peer interaction from their male peers. It can only speculated that hyperactivity, an externalizing disorder, may manifest itself in boys with SEN playing the class clown and therefore being perceived as funny by their male peers. In line with this, Jonkmann et al. (2009) showed that high popularity in seventh graders could be predicted by positive and deviant behavior alike.

Another explanation for low interaction with peers with SEN could be the attitude of peers with no SEN toward students with SEN. Therefore, hypothesis 2 was related to the predictive validity of the individual attitudes of students without SEN as well as the respective mean class attitude. It was anticipated that the individual and mean class attitudes of students without SEN toward their peers with SEN could predict the interactions of students with SEN during breaks. For boys, the cross-sectional data on T1 show that the individual attitudes of students without SEN toward their peers with SEN predicted their interactions with peers with SEN at T1, while the mean class attitude was no significant predictor. At T2, this effect was the other way around: while the individual attitude was not significantly linked to the peer interactions of students with SEN, the mean class attitudes were related to the interactions. Therefore, improving boys' attitudes toward students with SEN could be a relevant factor for increasing the social participation of their male peers with SEN. Like other studies, this study also indicates that, for the male sample, direct contact is positively linked to students' attitudes (MacMillan et al., 2013). For teachers, this means promoting high quality contacts between students with and without SEN in classes.

The results of the female sample were even more complex. The cross-sectional data for the first measurement showed a negative effect of the mean class attitudes. This means that the more negative the mean class attitudes of girls toward their peers with SEN are, the more often individual students had contact with their female peers with SEN. One possible interpretation of this result could be that individual girls are aware that their peers have rather negative attitudes toward students with SEN and they therefore try to compensate for this through socially desirable behavior or care. However, the longitudinal analysis showed no significant results for both samples, neither for the individual attitude nor for the mean class attitude. In line with this result, one must bear in mind that the question of attitudes toward peers with SEN is rather theoretical (referring to an imaginary student who was new in the class). Therefore, the predictor was more theoretical, while the criterion was real peer interactions with real students with SEN. Future research should focus on the real attitudes toward the actual students with SEN in the class and link this to the social participation of the students with SEN in order to increase the external validity and practical relevance. For teachers, the findings imply that they have to ensure social inclusion of all students, and that is not something that can be easily aimed for. However, there are still some possibilities for teachers to foster students' social participation (see the review of Hassani et al., 2020). Creating a positive climate (e.g., in the sense of positive attitudes toward students with SEN) might be an important topic and teachers need to be aware of its power. Further, teachers should also foster students' social competences in order to avoid behavior problems - not solely of students without SEN but also of those with SEN.

\section{LIMITATIONS}

This study provides more insight into the possible reasons for students without SEN having fewer interactions with their peers with SEN than with peers without SEN during their breaks. Some limitations of this study need to be pointed out: First, as mentioned before, a self-assessments was used to rate students' social behavior. However, self-report questionnaires may not actually reflect real behavior, and could be biased due to social desirability or other effects, such as wanting to be part of the group or "cool" (Müller et al., 2013). To avoid such effects, longitudinal observations by independent observers in classrooms would be necessary. In addition, scores of the SDQ were used as indicators of social behavior. The SDQ is rather a proxy measure of social behavior and it is used as a screening measure for diagnosing psychiatric disorders. Moreover, a further 
critical issue is the operationalization of students with SEN. Previous research in Austria (Schwab et al., 2015b) clearly pointed out a lack of transparency and clarity in the diagnosing process. It might be the case that some students who have SEN are not diagnosed as such. Even if the focus is only on students with SEN with respect to learning disabilities, the group will be fairly heterogeneous. Another limitation is the use of vignettes to assess students' attitudes toward peers with learning disabilities. Especially because associations were made within this study between the attitudes toward hypothetical students and the relationship with actual peers in classes. As Schwab (2018b) showed, students may not be able to make a connection between the hypothetical case vignettes and their actual peers in class. Last but not least, for reliable causal interpretation, it would also be necessary to have more measurement points and use a cross-lagged-panel design.

In spite of these limitations, this study pointed out that the need for more insight into possible predictors of low social participation among students with SEN and the necessity of more longitudinal research, as results often show different patterns.

\section{DATA AVAILABILITY STATEMENT}

The data analyzed in this study is subject to the following licenses/restrictions: Due to the granting of anonymity and data

\section{REFERENCES}

Aboud, F. E., and Mendelson, M. J. (1996). "Determinants of friendships selection and quality: developmental perspectives," in The Company they Keep: Friendship in Childhood and Adolescence, 1st Edn, eds W. M. Bukowski, A. F. Newbomb, and W. W. Hartup (New York: Cambridge University Press), 87-112.

Ajzen, I. (1991). The theory of planned behavior. Organ. Behav. Hum. Decision Process. 50, 179-211.

Allport, G. W. (1935). “Attitudes”, in A Handbook of Social Psychology, ed. C. A. Murchison (Worcester, MA: Clark University Press), 798-844.

Allport, G. W. (1954). The Nature of Prejudice. New York: Doubleday Anchor Books.

Armstrong, M., Morris, C., Abraham, C., Ukoumunne, O. C., and Tarrant, M. (2016a). Children's contact with people with disabilities and their attitudes towards disability: a cross-sectional study. Disabil. Rehabil. 38, 879-888. doi: 10.3109/09638288.2015.1074727

Armstrong, M., Morris, C., Tarrant, M., Abraham, C., and Horton, M. C. (2016b). Rasch analysis of the chedoke-mcmaster attitudes towards children with handicaps scale. Disabil. Rehabil. 39, 281-290. doi: 10.3109/09638288.2016. 1140833

Bajzek, V., Helmhart, M., Pilz, A., and Stoimaier, J. (2014). "SchülerInnen mit sonderpädagogischem Förderbedarf in Integrationsklassen - Wie integriert sind sie wirklich?", in Ausschnitte Aus der Grazer Inklusionsforschung, ed. S. Schwab (Hamburg: Kovać), 47-70.

Bossaert, G., Colpin, H., Pijl, S. J., and Petry, K. (2013). Truly included? a literature study focusing on the social dimension of inclusion in education. Int. J. Inclusive Educ. 17, 60-79. doi: 10.1080/13603116.2011.580464

Bossaert, G., and Petry, K. (2013). Factorial validity of the Chedoke-McMaster attitudes towards children with handicaps scale (CATCH). Res. Dev. Disab. 34, 1336-1345. doi: 10.1016/j.ridd.2013.01.007

de Boer, A., and Pijl, S. P. (2016). The acceptance and rejection of peers with ADHD and ASD in general secondary education. J. Educ. Res. 109, 325-332. doi: $10.1080 / 00220671.2014 .958812$ protection agreements, the dataset analyzed for this study is only available upon reasonable request from the corresponding author. Requests to access these datasets should be directed to SS, susanne.schwab@univie.ac.at.

\section{ETHICS STATEMENT}

The research was approved by the Regional School Authorities of Styria, Lower Austria, and Burgenland. Written informed consent to participate in this study was provided by the participants legal guardian.

\section{AUTHOR CONTRIBUTIONS}

SS, NT, and ML have jointly designed the manuscript and gave feedback and revised everything. ML was responsible for the data collection and supported mainly in the writing of the method and the results. NT did the analyses and authored the results. SS wrote the introduction and discussion. All authors agreed to be accountable for the content of the work.

\section{FUNDING}

The University of Vienna funded the open access fee.

de Boer, A., Pijl, S. J., Post, W., and Minnaert, A. (2013). Peer acceptance and friendships of students with disabilities in general education: the role of child, peer, and classroom variables. Soc. Dev. 22, 831-844.

DeVries, J. M., Voß, S., and Gebhardt, M. (2018). Do learners with special education needs really feel included? evidence from the perception inclusion questionnaire and strengths and difficulties questionnaire. Res. Dev. Disabil. 83, 28-36. doi: 10.1016/j.ridd.2018.07.007

Eagly, A. H., and Chaiken, S. (1998). "Attitude structure and function," in The Handbook of Social Psychology, eds D. T. Gilbert, S. T. Fiske, and G. Lindzey (New York: McGraw - Hill), 269-322.

Festinger, L. (1957). A Theory of Cognitive Dissonance. Stanford, CA: Stanford University Press.

Gebhardt, M., Krammer, M., Schwab, S., Rossmann, P., and Gasteiger-Klicpera, B. (2013). What is behind the diagnosis of learning disabilities in Austrian schools? an empirical evaluation of the diagnostic process. Int. J. Special Educ. $28,160-166$.

George, A. C., and Schwab, S. (2019). "Österreichs integrationsklassen: kompetenzdefizite durch soziale benachteiligung? ein vergleich zwischen integrations- und regelklassen," in Fünf Jahre Flächendeckende Bildungsstandardüberprüfungen in Österreich, eds C. Schreiner, C. Wiesner, A. C. George, K. Pacher, and M. Pointinger (Münster: Waxmann), 103-114.

Goodman, A., and Goodman, R. (2011). Population mean scores predict child mental disorder rates: validating SDQ prevalence estimators in Britain. J. Child Psychol. Psychiatry 52, 100-108. doi: 10.1111/j.1469-7610.2010.02 278.x

Grütter, J., Gasser, L., Zuffianò, A., and Meyer, B. (2018). Promoting inclusion: the mediating role of change in trust and sympathy. Child Dev. 89, 414-430.

Hassani, S., Aroni, K., Toulia, A., Alves, S., Górel, G., Lóper, M. F., et al. (2020). School-based Interventions to Support Student Participation. a Comparison of Different Programs. Results from the Friend-Ship Project. Vienna: University of Vienna.

Henke, T., Bogda, K., Lambrecht, J., Bosse, S., Koch, H., Maaz, K., et al. (2017). Will you be my friend? a multilevel network analysis of friendships of students with and without special educational needs backgrounds in inclusive classrooms. 
Zeitschrift für Erziehungswissenschaft 20, 449-474. doi: 10.1007/s11618-0170767-x

Jones, A. P., and Frederickson, N. (2010). Multi-informant predictors of social inclusion for students with autism spectrum disorders attending mainstream school. J. Autism. Dev. Disord. 40, 1094-1103. doi: 10.1007/s10803-010-0957-3

Jonkmann, K., Trautwein, U., and Lüdtke, O. (2009). Social dominance in adolescence: the moderating role of the classroom context and behavioral heterogeneity. Child Dev. 80, 338-355. doi: 10.1111/j.1467-8624.2009.01264.x

Keith, J. M., Bennetto, L., and Rogge, R. D. (2015). The relationship between contact and attitudes: reducing prejudice toward individuals with intellectual and developmental disabilities. Res. Dev. Disabil. 47, 14-26. doi: 10.1016/j.ridd. 2015.07.032

Kidger, J., Araya, R., Donovan, J., and Gunnell, D. (2012). The effect of the school environment on the emotional health of adolescents: a systematic review. Pediatrics 129, 925-949. doi: 10.1542/peds.2011-2248

Klasen, H., Woerner, W., Wolke, D., Meyer, R., Overmeyer, S., Kaschnitz, W., et al. (2000). Comparing the german versions of the strengths and difficulties questionnaire (SDQ-Deu) and the child behavior checklist. Eur. Child Adolesc. Psychiatry 9, 271-276. doi: 10.1007/s007870070030

Koster, M., Nakken, H., Pijl, S. J., and van Houten, E. J. (2009). Being part of the peer group: a literature study focussing on the social dimension of inclusion in education. Int. J. Inclusive Educ. 13, 117-140. doi: 10.1080/13603110701284680

Låftman, S. B., and Östberg, V. (2006). The pros and cons of social relations: an analysis of adolescents health complaints. Soc. Sci. Med. 63, 611-623. doi: 10.1016/j.socscimed.2006.02.005

Lu, T., Lin, S., Ji, L., Liu, L., Chen, X., and French, D. C. (2018). Longitudinal associations between popularity and aggression in chinese middle and high school adolescents. Dev. Psychol. 54, 2291-2301. doi: 10.1037/dev0000591

MacMillan, M., Tarrant, M., Abraham, C., and Morris, C. (2013). The association between children's contact with people with disabilities and their attitudes towards disability: a systematic review. Dev. Med. Child Neurol. 56, 529-546. doi: $10.1111 /$ dmcn. 12326

Mamas, C., and Avramidis, E. (2013). Promoting social interaction in the inclusive classroom: lessons from inclusive schools in England and Cyprus. Learn. Cult. Soc. Interact. 2, 217-226. doi: 10.1016/j.lcsi.2013.07.001

Mamas, C., Bjorklund, P., Daly, A. J., and Moukarzel, S. (2020). Friendship and support networks among students with disabilities in middle school. Int. J. Educ. Res. 103:101608. doi: 10.1016/j.ijer.2020.101608

Mand, J. (2007). Social position of special needs pupils in classroom: a comparison between german special schools for pupils with learning difficulties and integrated primary school classes. Eur. J. Special Needs Educ. 1, 7-14. doi: 10.1080/08856250601082182

Mjaavatn, P. E., Frostad, P., and Pijl, S. J. (2016). Adolescents: differences in friendship patterns related to gender. Issues Educ. Res. 26, 45-64.

Müller, C. M., Begert, T., Hofmann, V., and Studer, F. (2013). Effekte der Klassenzusammensetzung auf individuelles schulisches problemverhalten welche rolle spielt das verhalten der gesamtklasse, der ;coolen", der ;extremen" und der persönlichen freunde? (effects of class composition on individual problem behaviour at school - what role does the behaviour of the whole class, the "cool", the "extreme" and personal friends play). Zeitschrift für Pädagogik $59,722-742$.

Nepi, L. D., Fioravanti, J., Nannini, P., and Peru, A. (2015). Social acceptance and the choosing of favourite classmates: a comparison between students with special educational needs and typically developing students in a context of full inclusion. Br. J. Special Educ. 42, 319-337. doi: 10.1111/1467-8578.12096

Newcomb, A. F., Bukowski, W. M., and Pattee, L. (1993). Children's peer relations: a meta-analytic review of popular, rejected, neglected, controversial, and average sociometric status. Psychol. Bull. 113, 99-128. doi: 10.1037/0033-2909. 113.1.99

Petry, K. (2018). The relationship between class attitudes toward peers with a disability and peer acceptance, friendships and peer interactions of students with a disability in regular secondary schools. Eur. J. Special Needs Educ. 33, 254-268. doi: 10.1080/08856257.2018.1424782
Pettigrew, T. F., and Tropp, L. R. (2000). "Does inter-group contact reduce prejudice: recent meta-analytic findings," in Reducing Prejudice and Discrimination. The Claremont Symposium on Applied Social Psychology, ed. S. Oskamp (Mahwah, NJ: Lawrence Erlbaum Associates), 93-114.

Rosenbaum, P., Armstrong, R., and King, S. (1986). Children's attitudes toward disabled peers: a self-report measure. J. Pediatr. Psychol. 11, 517-530. doi: 10.1093/jpepsy/11.4.517

Schwab, S. (2014). Schulische Integration, Soziale Partizipation und Emotionales Wohlbefinden in der Schule. Ergebnisse einer empirischen Längsschnittstudie (Inclusive Education, Social Participation and Emotional Well-being in School. Results from an Empirical Longitudinal Study. Münster: Lit. Verlag.

Schwab, S. (2015). ,Einflussfaktoren auf die Einstellung von schülerinnen gegenüber peers mit unterschiedlichen Behinderungen (determinants of students' attitudes towards peers with different kinds of disabilities. Zeitschrift für Entwicklungspsychologie und Pädagogische Psychologie 47, 177-187.

Schwab, S. (2017). The impact of contact on students attitudes towards peers with disabilities. Res. Dev. Disabil. 62, 160-165. doi: 10.1016/j.ridd.2017.01.015

Schwab, S. (2018a). Attitudes Towards Inclusive Schooling. A study on Students Teachers and Parents Attitudes. Münster: Waxmann Verlag.

Schwab, S. (2018b). "Peer-relations of students with special educational needs in inclusive education," in Diritti Cittadinanza Inclusione, eds S. Polenghi, M. Fiorucci, and L. Agostinetto (Rovato: Pensa MultiMedia), $15-24$.

Schwab, S. (2020). Inclusive and Special Education in Europe. Oxford Research Encylopedia of Education. Oxford: Oxford University Press.

Schwab, S., Gebhardt, M., Hessels, M. G. P., and Nusser, L. (2016). Predicting a high rate of self-assessed and parent-assessed peer problems - is it typical for students with disabilities? Res. Dev. Disabil. 4, 196-204. doi: 10.1016/j.ridd. 2015.11.026

Schwab, S., Gebhardt, M., Krammer, M., and Gasteiger-Klicpera, B. (2015a). ,Linking self-rated social inclusion to social behaviour. an empirical study of students with and without special education needs in secondary schools. Eur. J. Special Needs Educ. 30, 1-14.

Schwab, S., Hessels, M. G. P., Obendrauf, T., Polanig, M. C., and Wölflingseder, L. (2015b). Assessing special educational needs in Austria: description of labeling practices and their evolution from 1996 to 2013. J. Cogn. Educ. Psychol. 14, 329-342. doi: 10.1891/1945-8959.14.3.329

Schwab, S., Rossman, P., Tanzer, N., Hagn, J., Oitzinger, S., Thurner, V., et al. (2015c). ,Schulisches wohlbefinden von schülerinnen mit und ohne sonderpädagogischen förderbedarf. integrations- und regelklassen im vergleich (school well-being of students with and without special educational needs. comparison of integration and regular classes). Zeitschrift für Kinder- und Jugendpsychatrie 43, 265-274.

Underwood, M. K. (2004). "Gender and peer relations: are the two gender cultures really all that different?," in Children's Peer Relations: From Development to Intervention, eds J. B. Kupersmidt and K. A. Dodge (Washington, DC: American Psychological Association), 21-36. doi: 10.1037/10653002

Conflict of Interest: The authors declare that the research was conducted in the absence of any commercial or financial relationships that could be construed as a potential conflict of interest.

The reviewer CM declared a past co-authorship with one of the authors SS to the handling Editor.

Copyright (c) 2021 Schwab, Lehofer and Tanzer. This is an open-access article distributed under the terms of the Creative Commons Attribution License (CC BY). The use, distribution or reproduction in other forums is permitted, provided the original author(s) and the copyright owner(s) are credited and that the original publication in this journal is cited, in accordance with accepted academic practice. No use, distribution or reproduction is permitted which does not comply with these terms. 